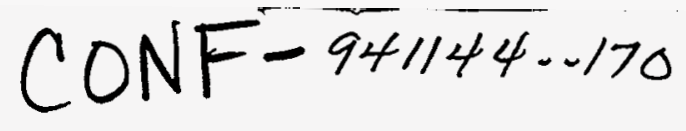

\title{
MICROSTRUCTURAL CHARACTERIZATION OF IRON IMPLANTED SAPPHIRE NANOCOMPOSITES
}

\author{
SHELLY X. REN, AND CARL J. MCHARGUE \\ Department of Materials Science and Engineering \\ The University of Tennessee, Knoxville, TN 37996 \\ L. F. ALLARD, Y. CHEN, J. D. HUNN, B. N. LUCAS AND R. K. WILLIAMS \\ Oak Ridge National Laboratory, Oak Ridge, TN 37831
}

\section{ABSTRACT}

Nanocomposites of iron in sapphire $\left(\alpha-\mathrm{Al}_{2} \mathrm{O}_{3}\right)$ prepared by ion implantation have been studied as a model to investigate the potential of such materials for applications in high technology areas. The implantation was performed with $160 \mathrm{keV}$ ions at several doses; the nanocomposites were then annealed at selected temperatures between 700 and $1400^{\circ} \mathrm{C}$ in an $\mathrm{Ar}$ $4 \% \mathrm{H}_{2}$ atmosphere for 1 hour. Rutherford backscattering spectroscopy and high resolution transmission electron microscopy (TEM) were used to characterize the structure of these nanocomposites. Measurements showed that damage depth extended to about $300 \mathrm{~nm}$ and the embedded iron extended to about $200 \mathrm{~nm}$. This region became amorphous when the fluence reaches $2 \times 10^{17} \mathrm{Fe} / \mathrm{cm}^{2}$ at this energy. Thermal annealing could be used to restore the crystallinity to the damaged near-surface region, to form the metallic colloids, and also to coarsen the precipitates. In the case of high dose implantation, oriented precipitates with diameters of 2 to $3 \mathrm{~nm}$ were identified by TEM techniques as $\alpha$-Fe which had the following orientation relationship with the sapphire matrix: $\left.\langle 111\rangle_{\mathrm{Fe}} \|<310\right\rangle_{\text {Sapphire }}$ and $\{01 \overline{1}\}_{\mathrm{Fe}} \|\{006\}_{\text {Sapphire. }}$. The optical density and luminescence spectra were also measured. The predominant defects were oxygen vacancies with two electrons ( $F$ center) at the known absorption peak of $200 \mathrm{~nm}$.

\section{INTRODUCTION}

Ion implantation has shown considerable promise as a means of modifying the near-surface properties of a wide range of materials such as metals and semiconductors. Recently, heavy metal ions have also been used to alter the physical, chemical, electrical, optical, and mechanical properties of ceramic materials. These modified materials often possess unique properties useful for high technology applications. A fundamental understanding of the relationship between the microstructures and properties of nanocomposites produced by implantation is essential for this new material development. In the study, a near surface layer of iron impurities was implanted into $\alpha-\mathrm{Al}_{2} \mathrm{O}_{3}$ single crystal substrates which were then heat treated in a reducing environment. The resulting microstructural changes were characterized with high resolution transmission electron microscopy (TEM), Rutherford backscattering spectroscopy (RBS), and their optical properties were also measured.

\section{EXPERIMENTAL PROCEDURES AND TECHNIQUES}

High purity single crystal sapphire $\left(\alpha-\mathrm{Al}_{2} \mathrm{O}_{3}\right)$ disks (c-axis oriented) with an optical-grade polish were used as substrates for ion beam implantation. Prior to implantation, the substrates were annealed at $1350^{\circ} \mathrm{C}$ in flowing air for 120 hours to remove the residual polishing damage and organic contaminants on the surface.

The substrate specimens were implanted with $160 \mathrm{keV} 56 \mathrm{Fe}$ ions at selected doses in the range from $4 \times 10^{16} \mathrm{Fe} / \mathrm{cm}^{2}$ to $2 \times 10^{17} \mathrm{Fe} / \mathrm{cm}^{2}$ at room temperature in the Surface Modification and Characterization Facility at the Oak Ridge National Laboratory. The implantation was 


\section{DISCLAIMER}

Portions of this document may be illegible in electronic image products. Images are produced from the best available original document. 
performed with the ion beam about $7^{\circ}$ off-normal to minimize channeling effects. The asimplanted samples with each dose level were then annealed for 1 hour in a mixture of $\mathrm{Ar}-4 \% \mathrm{H}_{2}$ atmosphere at $700,900,1100$, and $1400^{\circ} \mathrm{C}$ respectively.

RBS measurements were performed with a beam of $2 \mathrm{MeV} \mathrm{He}$. Channeling spectra were obtained with the beam aligned along the c-axis, and random spectra by rotating the sample off c-axis.

Cross-sectioned TEM specimens are particularly well suited to the study of near surface details since they make it possible to determine the depth dependence of the composition and microstructural features. However, the preparation of such single crystal ceramic specimens is extremely difficult because of the brittle nature and small size of the specimens. In this study, a modified technique for preparing cross-sectioned TEM specimen was developed, which minimized cracking during the thinning processes. Two pieces of $1 \times 2 \times 6 \mathrm{~mm}$ slices were mechanically cut from the implanted specimens, glued with the implanted surfaces face-to-face with M-bond type 610 adhesive epoxy to form a sandwich shaped specimen. The freshly glued cross sections were squeezed in a vise so that the glue thickness was minimized. The epoxy was allowed to cure at $80^{\circ} \mathrm{C}$ in an oven overnight. The glued specimen was then sliced perpendicularly to the glued interface, resulting in a specimen with a thickness of $400-500 \mu \mathrm{m}$. One side of the slice was mechanically polished using $6 \mu \mathrm{m}$ and then $3 \mu \mathrm{m}$ diamond pastes. To minimize cracking during subsequent processes and also to help fit the sample into the TEM sample holder, the polished side was glued onto a carbon ring. The specimen was ground to 100 $\mu \mathrm{m}$ using $6 \mu \mathrm{m}$ diamond paste, and then dimpled to 20-25 $\mu \mathrm{m}$ in thickness. It was finally polished by $1 \mu \mathrm{m}$ diamond paste. Final thinning was performed using an ion mill until a hole could barely be seen.

The newly developed Hitachi HF-2000 field emission electron microscope operating at 200 $\mathrm{kV}$ was utilized for the TEM specimen observations. This facility has the advantage of high resolution images and an ultra fine $\mathrm{X}$-ray probe for EDS analysis.

Optical absorption measurements were performed at $25^{\circ} \mathrm{C}$ with a Perkins-Elmer lambda 9 spectrophotometer. A Spex Industries Model F212 was used for luminescence measurements.

\section{RESULTS AND DISCUSSION}

Figure 1(a) shows random and channeled RBS spectra for $\alpha-\mathrm{Al}_{2} \mathrm{O}_{3}$ implanted with $4 \times 10^{16}$ $\mathrm{Fe} / \mathrm{cm}^{2}$. The implanted ions were embedded to a maximum depth of about $200 \mathrm{~nm}$ with a Gaussian distribution centered around $100 \mathrm{~nm}$. Most of iron occupied interstitial sites as shown by the lack of channeling for the iron signal. The lattice damage extended to about $300 \mathrm{~nm}$ with a peak at about $150 \mathrm{~nm}$. At this dose, the damage peak in the channeling spectrum has not reached the random level indicating incomplete amorphization of the implanted region. Figure 1(b) shows a partial recovery of the lattice damage after annealing at $900^{\circ} \mathrm{C}$ for 1 hour in an Ar$4 \% \mathrm{H}_{2}$ atmosphere.
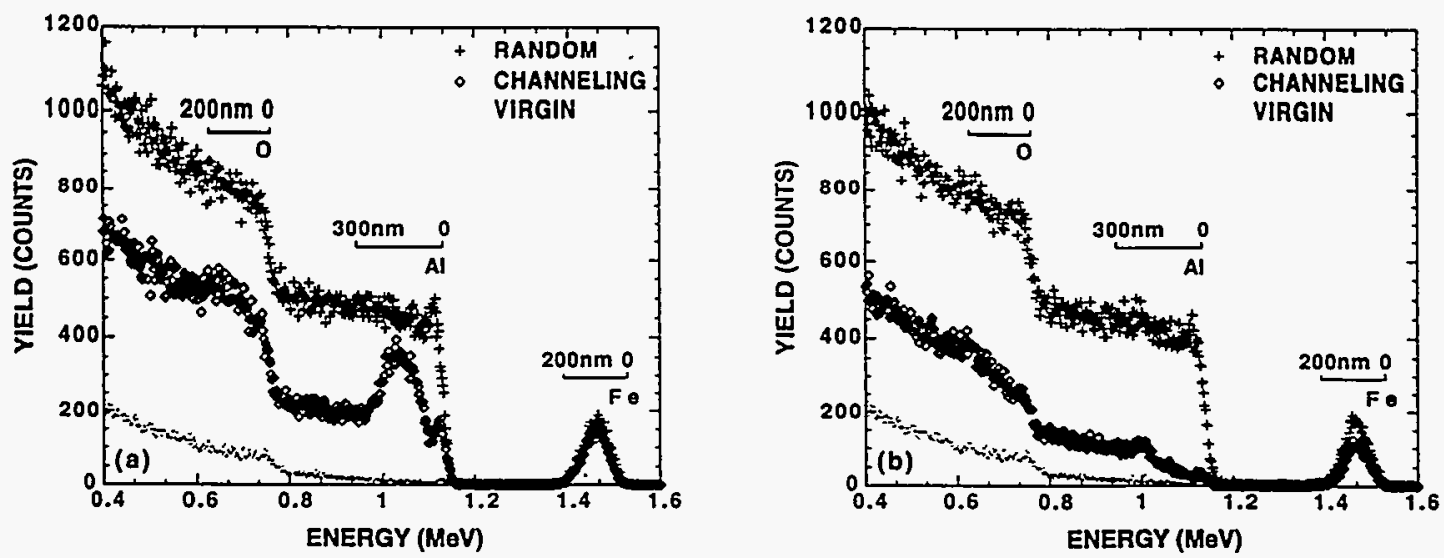

Figure 1. RBS spectra for $\alpha-\mathrm{Al}_{2} \mathrm{O}_{3}$ implanted with $4 \times 10^{16} \mathrm{Fe} / \mathrm{cm}^{2}$

(a) as implanted and (b) annealed for 1 hour at $900^{\circ} \mathrm{C}$ in $\mathrm{Ar}-4 \% \mathrm{H}_{2}$. 
Random and channeled RBS spectra for $\alpha-\mathrm{Al}_{2} \mathrm{O}_{3}$ implanted with $2 \times 10^{17} \mathrm{Fe} / \mathrm{cm}^{2}$ are shown in-Fig. 2(a). At-this-dose the-damage-peak in-the-ehanneling spectrum has reached the random level indicating that the matrix became either amorphous or microcrystalline. Again, after the implanted sample was annealed at $900^{\circ} \mathrm{C}$ for 1 hour in an $\mathrm{Ar}-4 \% \mathrm{H}_{2}$ atmosphere, crystallinity was restored in the damaged region as shown in Fig. 2(b). The reduced iron peak. an obvious channeling effect, could be due to either some interstitial iron diffused to the substitutional sites or the formation of the oriented iron precipitates. A reduction in the yield from the iron and a shift of the iron peak to higher energy with increasing annealing temperature showed that the iron was diffusing to the surface and being lost by evaporation.
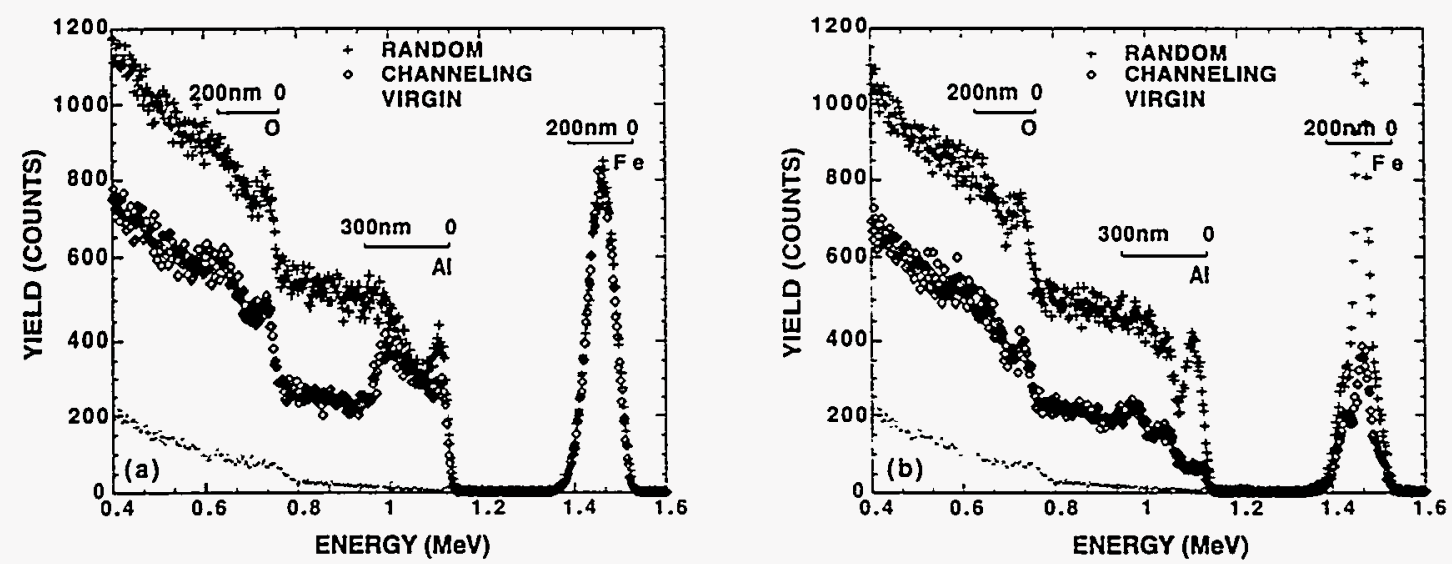

Figure 2. RBS spectra for $\alpha-\mathrm{Al}_{2} \mathrm{O}_{3}$ implanted with $2 \times 10^{17} \mathrm{Fe} / \mathrm{cm}^{2}$

(a) as implanted and (b) annealed for 1 hour at $900^{\circ} \mathrm{C}$ in $\mathrm{Ar}-4 \% \mathrm{H}_{2}$.

Figure 3(a) shows a micrograph of the cross-sectioned specimen of $\alpha-\mathrm{Al}_{2} \mathrm{O}_{3}$ implanted with $4 \times 10^{16} \mathrm{Fe} / \mathrm{cm}^{2}$. The damage layer extended about $300 \mathrm{~nm}$ below the surface. Previous conversion electron Mössbauer spectroscopy measurements indicated that about 0.18 of the implanted iron particles existed as $\mathrm{Fe}^{0}$, about 0.82 as $\mathrm{Fe}^{2+}[1]$. Figure 3(b) shows a high resolution micrograph of the same area. The lattice fringes provide strong evidence that the implanted layer remained crystalline. These direct observations are in good agreement with RBS measurements as shown in Fig. 1(a).
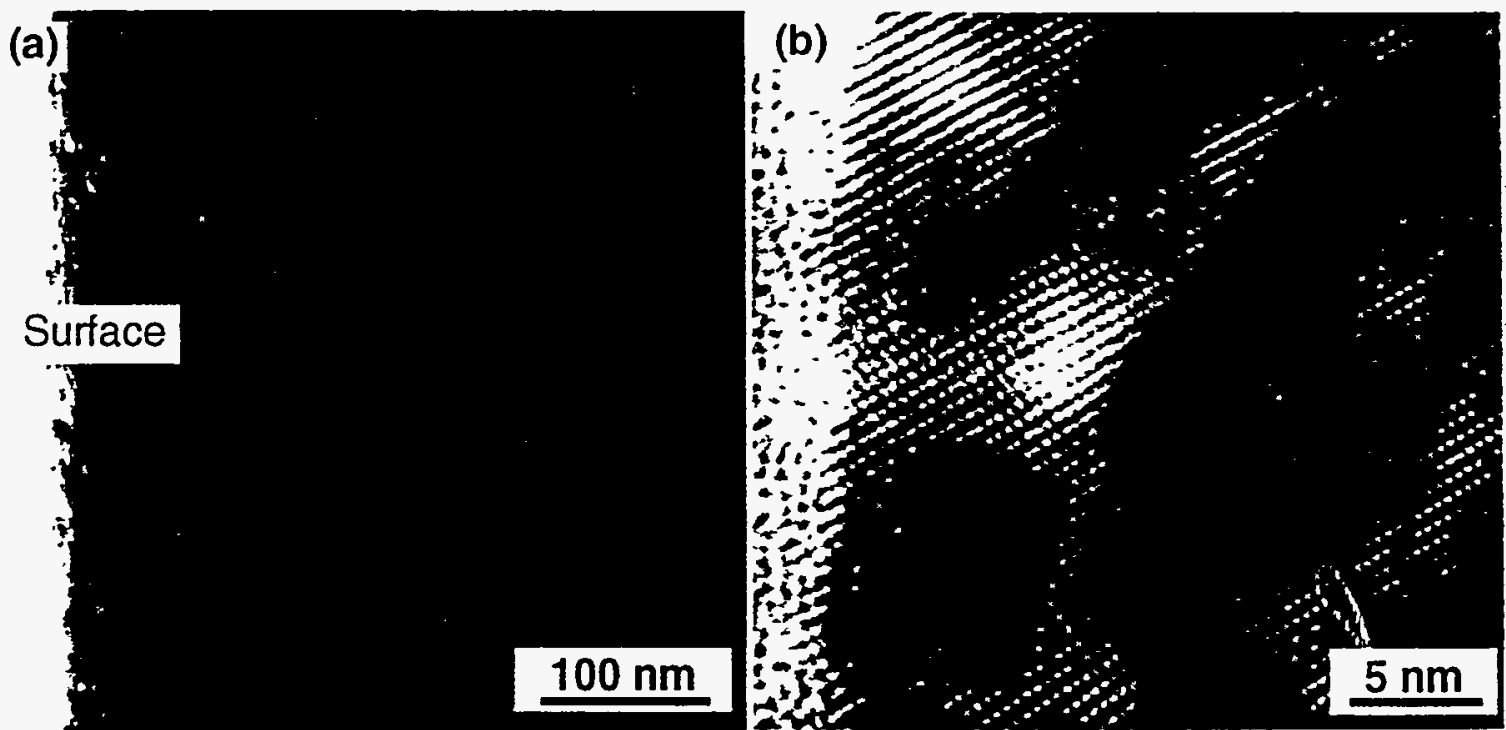

Figure 3. Micrograph of cross-sectioned specimen of $\alpha-\mathrm{Al}_{2} \mathrm{O}_{3}$ implanted with $4 \times 10^{16} \mathrm{Fe} / \mathrm{cm}^{2}$.

Precipitates with diameters ranging from 5 to $25 \mathrm{~nm}$ shown in Fig. 4(a) were found following annealing of sapphire implanted with $4 \times 10^{16} \mathrm{Fe} / \mathrm{cm}^{2}$ at $1100^{\circ} \mathrm{C}$ in $\mathrm{Ar}-4 \% \mathrm{H}_{2}$. Many 
of the precipitates appeared to be attended by voids. suggesting that mechanisms such as coalescence and Ostwald ripening could have occurred. The precipitates had a maximum diameter of about $50 \mathrm{~nm}$ when annealed at $1400^{\circ} \mathrm{C}$, as shown in Fig. $4(\mathrm{~b})$.
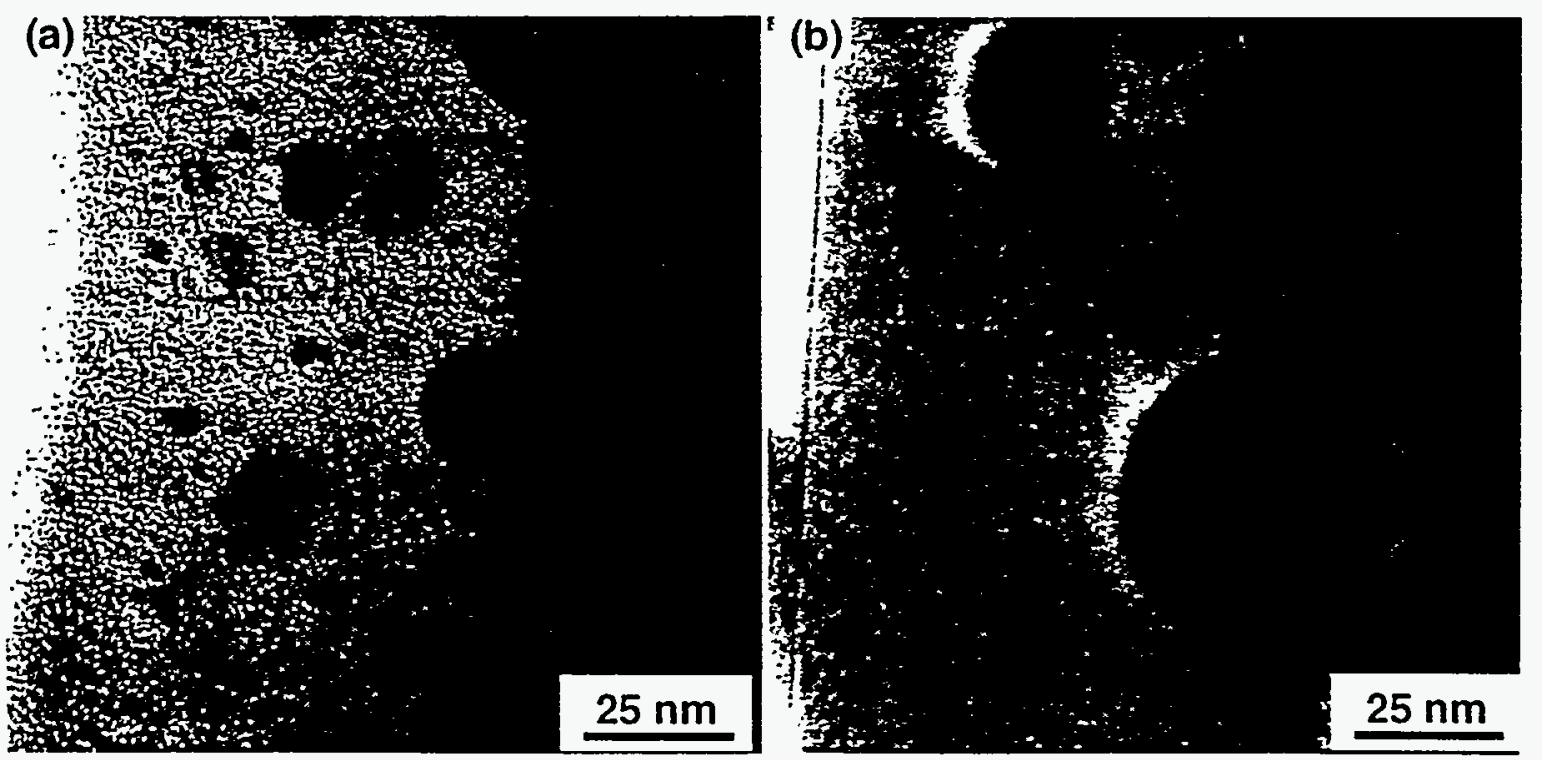

Figure 4. Micrograph of cross-sectioned specimen of $\alpha-\mathrm{Al}_{2} \mathrm{O}_{3}$ implanted with $4 \times 10^{16} \mathrm{Fe} / \mathrm{cm}^{2}$ (a) annealed for 1 hour at $1100^{\circ} \mathrm{C}$ in $\mathrm{Ar}-4 \% \mathrm{H}_{2}$; (b) annealed for 1 hour at $1400^{\circ} \mathrm{C}$ in $\mathrm{Ar}-4 \% \mathrm{H}_{2}$.

Figures 5(a) and 5(b) are the micrographs of the cross-sectioned specimen of sapphire implanted with $2 \times 10^{17} \mathrm{Fe} / \mathrm{cm}^{2}$. Oriented precipitates were observed in the amorphous $\mathrm{Al}_{2} \mathrm{O}_{3}$ matrix as shown in Fig. 5(b). EDS measurements indicated that these clusters were iron-rich. Selected area diffraction pattern from the same area is shown in Fig. 6(a). Two sets of patterns resulted from the combination of $\langle 310\rangle$ sapphire matrix and $\langle 111\rangle \alpha-\mathrm{Fe}$ as indexed in Fig. 6 (b) where the large spots represent the diffraction pattern of sapphire, and the small spots represent that of $\alpha-\mathrm{Fe}$. The diffuse $\alpha$-Fe pattern was due to the subtle misorientation of the precipitates. These 2 to $3 \mathrm{~nm}$ oriented precipitates in Fig. 5 were thus identified as body centered cubic $\alpha-F e$ and presented the following orientation relationship with the sapphire matrix: $\left.\langle 111\rangle_{\mathrm{Fe}} \|<310\right\rangle_{\text {Sapphire }}$ and $\{01 \overline{1}\}_{\mathrm{Fe}} \|\{006\}_{\text {Sapphire }}$.
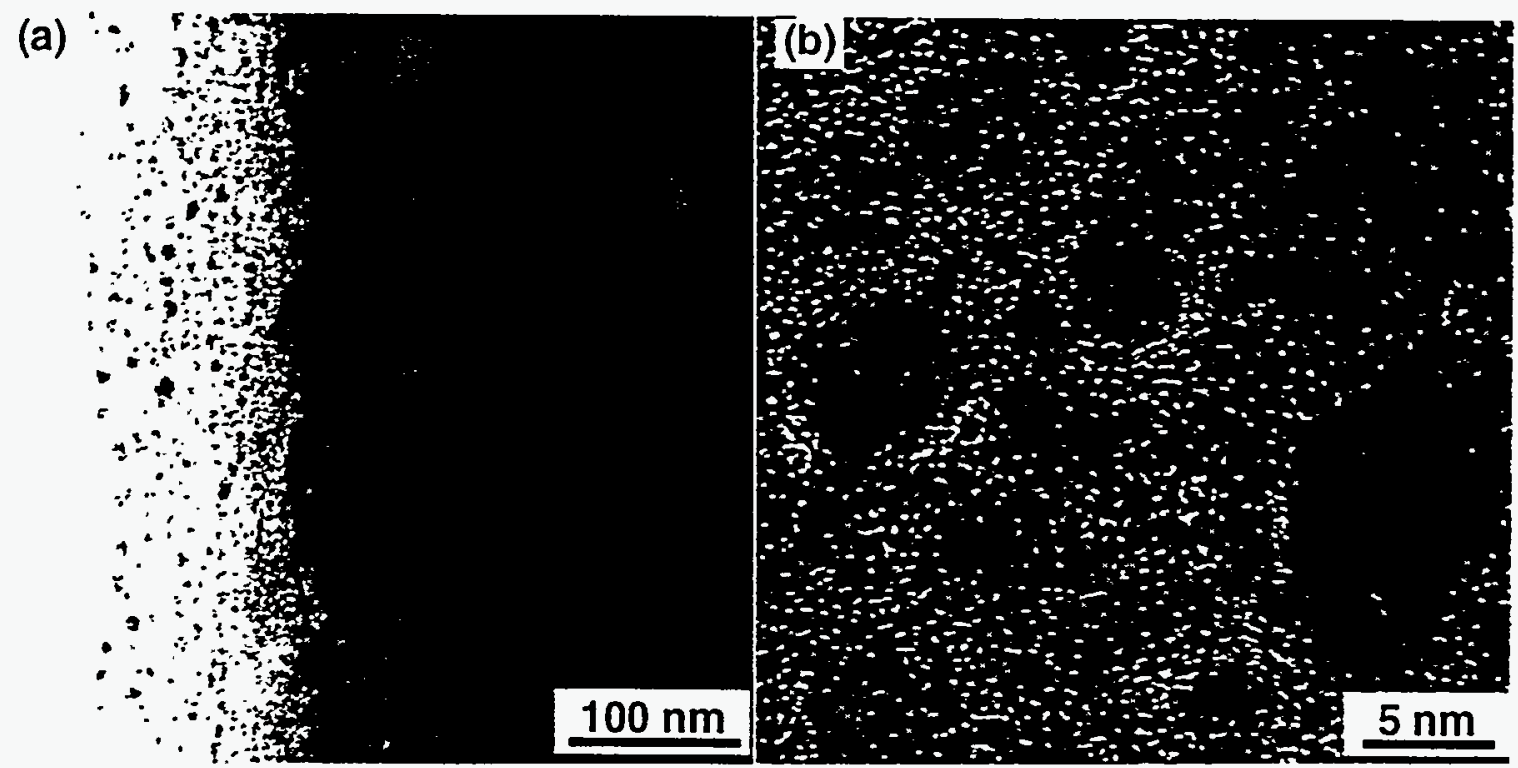

Figure 5. Micrograph of cross-sectioned specimen of $\alpha-\mathrm{Al}_{2} \mathrm{O}_{3}$ implanted with $2 \times 10^{17} \mathrm{Fe} / \mathrm{cm}^{2}$. 

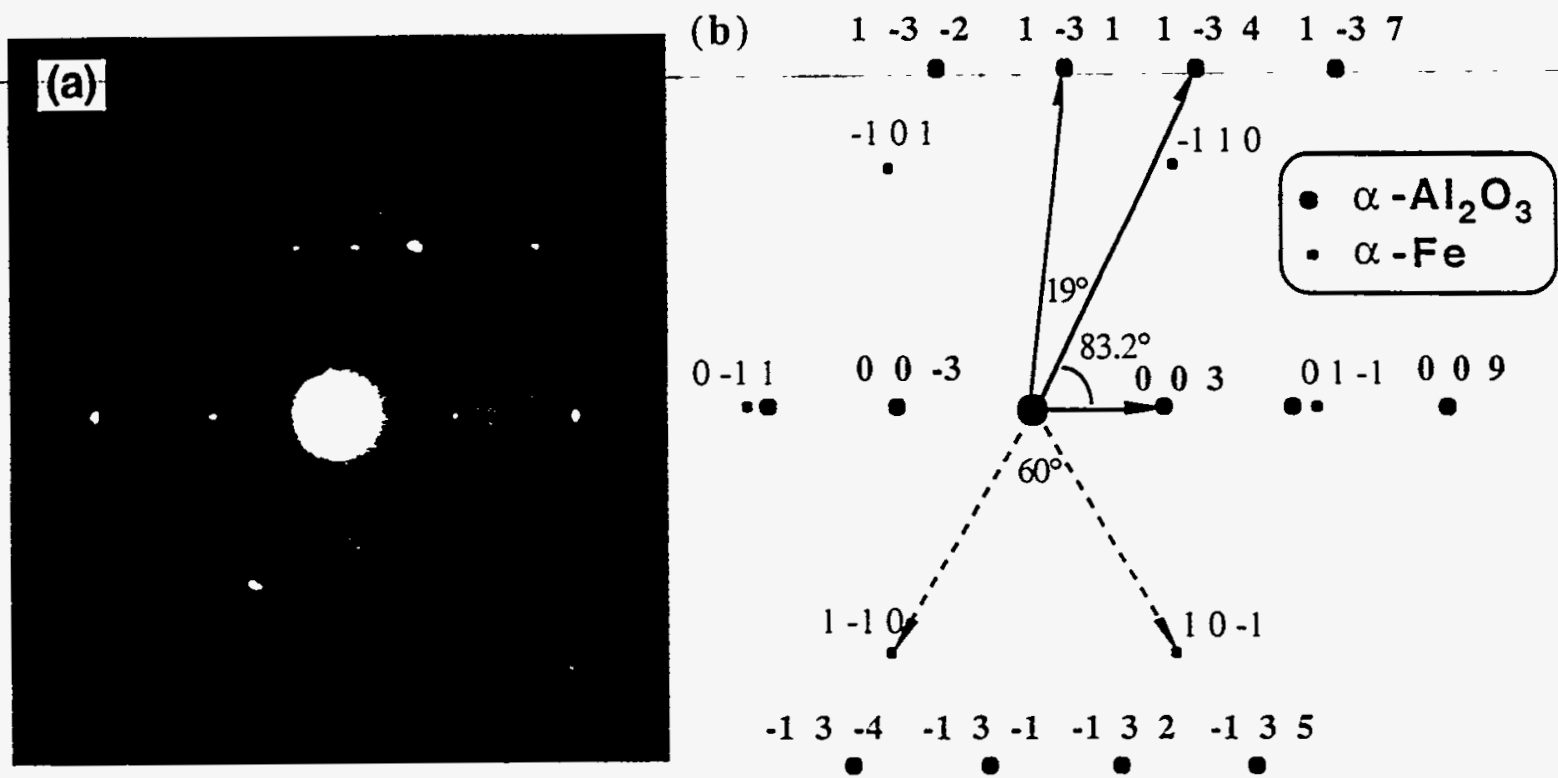

Figure 6. SAD patterns of cross-sectioned specimen of $\alpha-\mathrm{Al}_{2} \mathrm{O}_{3}$ implanted with $2 \times 10^{17} \mathrm{Fe} / \mathrm{cm}^{2}$ (a) experimental results and (b) calculated data.

Interestingly, in the samples implanted with $2 \times 10^{17} \mathrm{Fe} / \mathrm{cm}^{2}$ and annealed at $900^{\circ} \mathrm{C}$, the iron concentrated in a band about $25 \mathrm{~nm}$ wide at a depth of $50 \mathrm{~nm}$ below the surface as shown in Fig. 7. The distribution of iron in this band was not continuous, and the intermediate regions contained amorphous material. It is speculated that the discontinuity of the band resulted from the coalescence of the precipitates and the cavities as well, or was due to stresses generated by the difference in coefficient of thermal expansion. Elliptical $\alpha-F e$ particles of 10 to $40 \mathrm{~nm}$ in length were also found near the band.

(a)

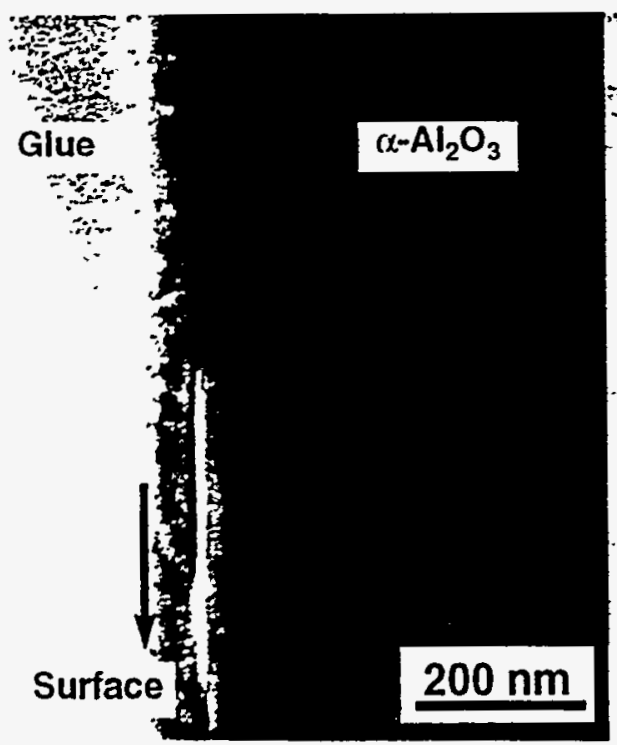

(b)

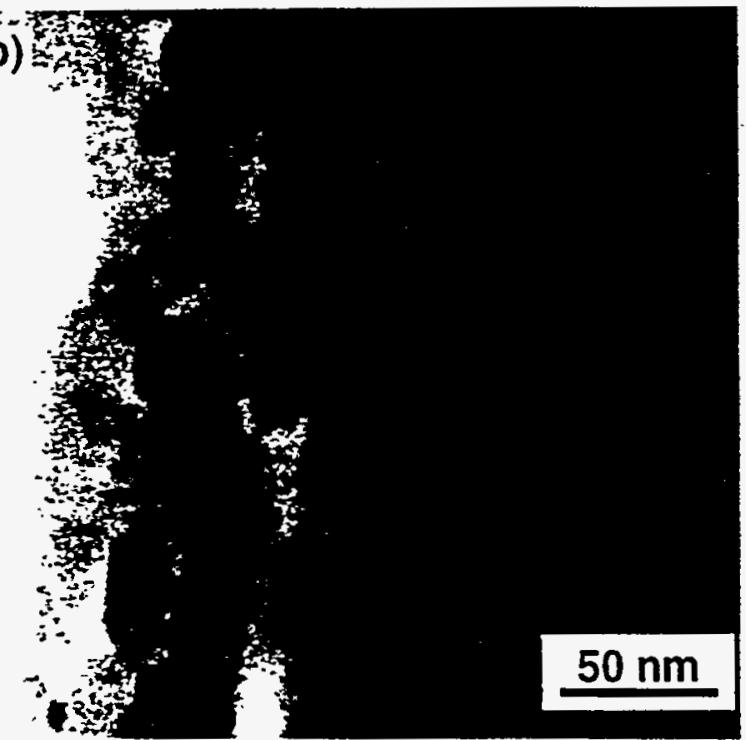

Figure 7. Micrograph of cross-sectioned specimen of $\alpha-\mathrm{Al}_{2} \mathrm{O}_{3}$ implanted with $2 \times 10^{17} \mathrm{Fe} / \mathrm{cm}^{2}$ and annealed $1 \mathrm{~h}$ in $\mathrm{Ar}-4 \% \mathrm{H}_{2}$ at $900^{\circ} \mathrm{C}$.

Optical absorption measurements, shown in Fig. 8(a), exhibit a strong absorption band at about $200 \mathrm{~nm}$. This absorption has been identified to be due to $\mathrm{F}$ centers (an oxygen vacancy containing two electrons) [2]. The optical density of this band, which is proportional to the concentration of the $\mathrm{F}$ centers, decreased as the annealing temperature increased. In the figure, the broad extinction band between 250 to $400 \mathrm{~nm}$ is attributed to Mie scattering from the precipitates. It is also noted that the optical density of this broad band increased as the annealing 
temperature increased. This observation is consistent with TEM measurements, in which the density of $\mathrm{Fe}$ precipitates increased with increasing annealing temperature. A luminescence technique was employed to identify both $\overline{\mathrm{F}}$ and $\mathrm{F}^{+}$centers (an oxygen vacancy containing one electron). Figure 8(b) illustrates the luminescence spectra obtained by excitation with $245 \mathrm{~nm}$ light for sapphire implanted with $4 \times 10^{16} \mathrm{Fe} / \mathrm{cm}^{2}$, which produced luminescence from both the $\mathrm{F}^{+}$and the $\mathrm{F}$ centers because this wavelength overlaps both absorption bands. The absorption peak at $330 \mathrm{~nm}$ has been attributed to $\mathrm{F}^{+}$centers, and the one at $420 \mathrm{~nm}$ to $\mathrm{F}$ centers. Annealing at $1100^{\circ} \mathrm{C}$ diminished the defect concentration and therefore the luminescence intensity (lower curve).
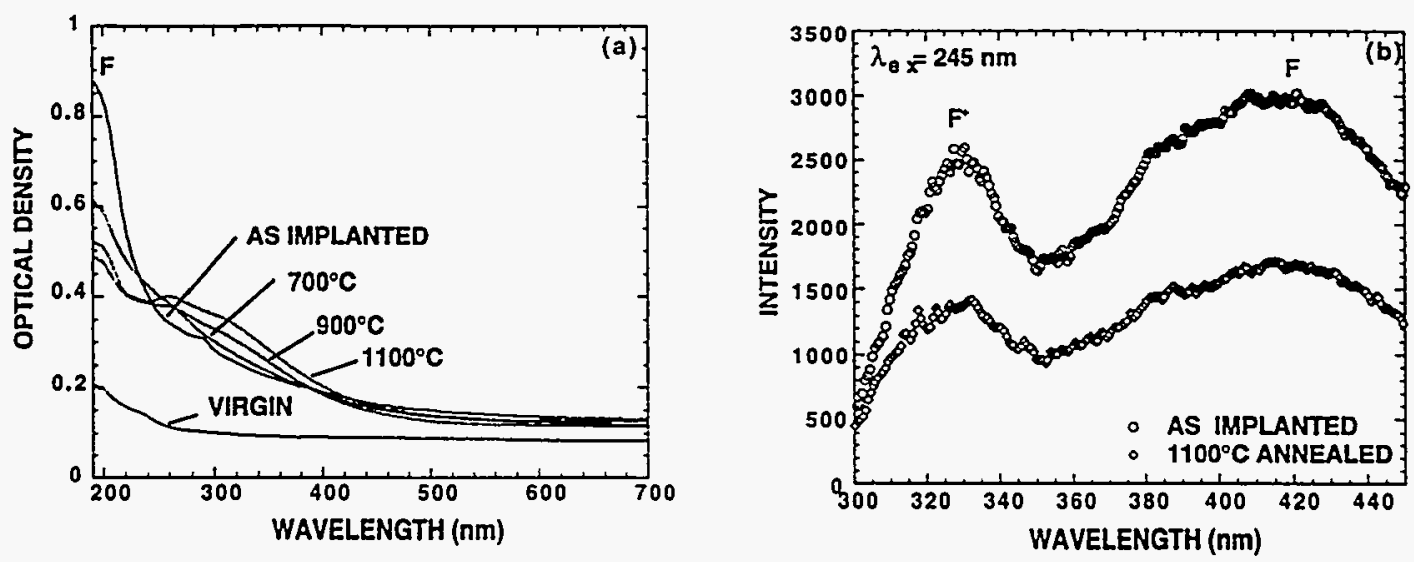

Figure 8. Optical (a) absorption and (b) luminescence spectra of $\alpha-\mathrm{Al}_{2} \mathrm{O}_{3}$ implanted with $4 \times 10^{16} \mathrm{Fe} / \mathrm{cm}^{2}$ and then annealed for $1 \mathrm{~h}$ in an $\mathrm{Ar}-4 \% \mathrm{H}_{2}$ atmosphere.

\section{CONCLUSIONS}

Implantation of $160 \mathrm{keV}{ }^{56} \mathrm{Fe}$ in $\alpha-\mathrm{Al}_{2} \mathrm{O}_{3}$ produced a damaged amorphous microstructure at a threshold fluence of $2 \times 10^{17} \mathrm{Fe} / \mathrm{cm}^{2}$ at room temperature. Most of the implanted iron was present as metallic $\alpha-F e$ precipitates as small as 2 to $3 \mathrm{~nm}$ at this fluence. The orientation relationship between the metallic $\alpha$-Fe precipitates and the sapphire matrix is identified as: $\left.\langle 111\rangle_{\mathrm{Fe}} \|<310\right\rangle_{\text {Sapphire }}$ and $\left\{01 \overline{1}_{\mathrm{Fe}} \|\{006\}_{\text {Sapphire }}\right.$. Annealing of the implanted specimens in an Ar$4 \% \mathrm{H}_{2}$ atmosphere led to the aggregation of metallic colloids, the coarsening of the precipitates, and finally the formation of a discontinuous band. The predominant defects were oxygen vacancies with two electrons ( $F$ centers) at an absorption peak of $200 \mathrm{~nm}$.

\section{ACKNOWLEDGMENTS}

This research is supported in part by the U. S. Department of Energy, Division of Materials Sciences and the Assistant Secretary for Energy Efficiency and Renewable Energy, Office of Transportation Technologies as part of the High Temperature Materials Laboratory User Program, under contract DE-AC05-84OR21400 with Martin Marietta Energy Systems, Inc.. We would also like to thank Weiju Ren, Debra Joslin and many staff members of ORNL for their help during this research.

\section{REFERENCES}

1. C. J. McHargue, P. S. Sklad, C. W. White, and G. C. Farlow, J. Mater. Res. 6 (10), 2145-2159 (1991)

2. B. D. Evans and M. Stapelbroek, Phys. Rev. B18 , 7089 (1978) 